\title{
APLIKASI POLIETILENA GLIKOL SEBAGAI PHASE CHANGE MATERIAL (PCM) PADA KAIN CAMPURAN POLIESTER/CATIONIC DYEABLE POLYESTER DAN POLIESTER/RAYON
}

\author{
APPLICATION OF POLYETHYLENE GLYCOL AS PHASE CHANGE MATERIAL \\ (PCM) ON POLYESTER/CATIONIC DYEABLE POLYESTER AND \\ POLYESTER/RAYON BLEND FABRICS
}

\author{
Jakariya Nugraha, Doni Sugiyana, Tatang Wahyudi \\ Balai Besar Tekstil, Jalan Jenderal Ahmad Yani No. 390 Bandung 40272 \\ Telp. (022) 7206214, 7206215, Fax (022) 7271288 \\ E-mail: bbt@kemenperin.go.id
}

Tanggal diterima: 31 Desember 2019, direvisi: 18 Desember 2020, disetujui terbit: 18 Desember 2020

\begin{abstract}
ABSTRAK
Pada saat ini pengembangan produk tekstil fungsional cukup pesat, salah satunya adalah produk tekstil fungsional yang memiliki sifat thermo-regulating. Untuk maksud tersebut, pada penelitian ini telah dilakukan penerapan phase change material (PCM) yang berbasis polietilena glikol (PEG) pada kain campuran poliester/cationic dyeable polyester (CDP) dan campuran poliester/rayon (T/R) dengan cara pad-dry-cure. Formula PCM yang digunakan merupakan campuran PEG (berat molekul 1000) 5\%/ N-metiloldihidroksietilenurea (N-MDHEU) 3\%/ katalis $\mathrm{MgCl}_{2} \quad 0,3 \%$ dalam suasana asam. Karakterisasi dan pengujan kain hasil percobaan dilakukan dengan menggunakan fourier transform infrared (FTIR), scanning electron microscope (SEM) dan differential scanning calorimeter (DSC). Hasil penelitian menunjukkan bahwa kain poliester/CDP yang diberi perlakuan memiliki aktivitas termal dengan nilai $\mathrm{T}(\mathrm{m})=36,95^{\circ} \mathrm{C}, \Delta \mathrm{Hf}=4,98 \mathrm{~J} / \mathrm{g}$ dan $\mathrm{T}(\mathrm{c})=20,06^{\circ} \mathrm{C}, \Delta \mathrm{Hc}=5,30 \mathrm{~J} / \mathrm{g}$, sedangkan kain $\mathrm{T} / \mathrm{R}$ yang juga diberi perlakuan mempunyai aktivitas termal dengan nilai $\mathrm{T}(\mathrm{m})=34,56^{\circ} \mathrm{C}, \Delta \mathrm{Hf}=0,079 \mathrm{~J} / \mathrm{g}$, dan $\mathrm{T}(\mathrm{c})=19,49^{\circ} \mathrm{C}$, $\Delta \mathrm{Hc}=0,024 \mathrm{~J} / \mathrm{g}$. Hasil uji pencucian terhadap kain hasil percobaan menunjukkan hasil yang belum optimal, dimana pada uji pencucian yang setara dengan 1 kali pencucian rumah tangga menunjukkan PCM masih terdegradasi dari permukaan kain.
\end{abstract}

Kata kunci: polietilena glikol, phase change materials, poliester/cationic dyeable polyester, poliester/rayon.

\section{ABSTRACT}

Functional textiles products are developing quite rapidly, one of the examples is the development of functional textile with thermo-regulating property. For this purpose, a research on the application of phase change material $(P C M)$ of polyethylene glycol (PEG) based onto polyester/cationic dyeable polyester (CDP) and polyester/rayon blend fabrics by pad-dry-cure method were carried out. The formula of PCM used in this study consists of 5\% PEG (molecular weight 1000), 3\% N-methyloldihydroxyethyleneurea ( $\mathrm{N}-\mathrm{MDHEU}$ ), and $0.3 \% \mathrm{MgCl}_{2}$ as catalyst under acidic condition. Characterization and testing of the treated fabrics were performed using Fourier transform infrared (FTIR), scanning electron microscope (SEM), and differential scanning calorimeter (DSC). The results showed that the treated polyester/CDP fabric had thermal activity with the values of $T(\mathrm{~m})=36.95^{\circ} \mathrm{C}, \Delta H f=4.98 \mathrm{~J} / \mathrm{g}$, and $T(\mathrm{c})=$ $20.06^{\circ} \mathrm{C}, \Delta H(c)=5.30 \mathrm{~J} / \mathrm{g}$, while the treated $T / R$ fabric had thermal activity with $T(\mathrm{~m})=34.56^{\circ} \mathrm{C}, \Delta H f=0.079 \mathrm{~J} / \mathrm{g}$, and $T(c)=19.49^{\circ} \mathrm{C}, \triangle H c=0.024 \mathrm{~J} / \mathrm{g}$. Durability to washing of both fabrics treated with PCM has not given the optimum result, considering in the washing test equivalent to 1 time of household washing, the treated fabrics showed degradation of PCM from the surface of the fabrics.

Keywords: polyethylene glycol, phase change materials, polyester/cationic dyeable polyester, polyester/rayon.

\section{PENDAHULUAN}

Pengembangan tekstil fungsional dan tekstil cerdas saat ini telah banyak dilakukan, diantaranya dengan cara mengaplikasikan bahan phase change materials (PCM) untuk menghasilkan tekstil yang mempunyai kemampuan pengaturan panas atau yang lebih dikenal dengan thermoregulated textiles. Suatu material PCM mempunyai kemampuan menyerap/melepaskan panas laten yang disertai perubahan fisik dari bentuk padat ke bentuk cair atau sebaliknya ketika suhu lingkungan mengalami perubahan. Berbagai jenis PCM tersedia dalam bentuk senyawa organik maupun anorganik, namun demikian, penggunaannya dalam bidang tekstil 
cenderung dalam bentuk senyawa organik seperti polietilena glikol dan parafin. ${ }^{1-5}$

Polietilena glikol (PEG) merupakan salah satu kandidat bahan yang dapat digunakan sebagai PCM untuk diaplikasikan pada kain atau bahan tekstil. Berbagai teknik penerapan PEG sebagai PCM pada kain atau bahan tekstil dapat dilakukan dengan berbagai macam teknik seperti pad-dry-cure dan electrospinning. ${ }^{6-10}$ Cara mengaplikasikan PEG pada bahan tekstil dapat dilakukan secara langsung dengan bantuan bahan pengikat silang (crosslinking agent) atau melalui proses enkapsulasi terlebih dahulu, proses grafting, dan kopolimerisasi. ${ }^{11-14}$ Dari sekian banyak teknik penerapan PEG sebagai bahan PCM pada kain/tekstil, teknik pad-dry-cure merupakan teknik yang cukup sederhana dan teknik ini masih banyak digunakan dalam proses penyempurnaan (finishing) di industri tekstil hingga saat ini.

Penelitian penerapan bahan polietilena glikol (PEG) sebagai bahan PCM pada tekstil telah diawali oleh Vigo dan Frost (1985) menggunakan PEG (berat molekul 600 dan 3360) dan material plastik dimetilpropanadiol/hidroksi metil propanediol. ${ }^{6}$ Penelitian ini menemukan bahwa kain dengan aplikasi PCM menghasilkan sifat thermoregulated lebih tinggi 2-2,5 kali dibanding kain tanpa aplikasi PCM. ${ }^{6}$ Penelitian lanjutan dilakukan dengan aplikasi PEG (berat molekul 1000/1450) dan bahan pengikat silang dimethylol dihydroxyethyleneurea (DMDHEU) dan katalis $\mathrm{MgCl}_{2}$ pada kain kapas dan campurannya dengan poliester serta polipropilen. ${ }^{15}$ Hasil penelitian ini menyimpulkan bahwa kondisi proses curing berpengaruh terhadap kandungan panas laten serta $\mathrm{T}(\mathrm{m})$ dan $\mathrm{T}(\mathrm{c})$ yang dihasilkan. ${ }^{15}$

Dalam penelitian ini dilakukan aplikasi PEG (BM 1000) pada kain campuran poliester/cationic dyeable polyester $(\mathrm{CDP})$ dan poliester/rayon (T/R) dengan bantuan crosslinking agent $\mathrm{N}$ metiloldihidroksietilenurea (N-MDHEU) serta katalis $\mathrm{MgCl}_{2}$ menggunakan metoda pad-dry-cure. Metode tersebut digunakan mengingat kelayakannya pada saat ini untuk dilakukan di industri tekstil.

\section{METODE}

\section{Bahan dan peralatan penelitian}

Bahan yang digunakan dalam penelitian ini kain campuran poliester/cationic dyeable polyester (CDP) jenis anyaman twill dengan gramasi $172 \mathrm{~g} / \mathrm{m}^{2}$, kain campuran poliester/rayon (T/R) anyaman polos $1 / 1$ dengan gramasi $213,3 \mathrm{~g} / \mathrm{m}^{2}$. Sedangkan bahan kimia terdiri atas polietilena glikol (BM 1000), $\mathrm{MgCl}_{2}$ dan asam sitrat produksi Merck. Crosslink agent $\mathrm{N}$-metilol dihidroksietilenurea (N-MDHEU) dan surfaktan nonionik berkualitas teknis produksi PT. Rudolf Chemicals.

\section{Persiapan larutan PCM}

Pembuatan larutan katalis $\mathrm{MgCl}_{2}$ /asam sitrat (rasio molar 5:1) dilakukan dengan melarutkan 101,65 gram $\mathrm{MgCl}_{2} \cdot 6 \mathrm{H}_{2} \mathrm{O}$ dan 21,01 gram asam sitrat dalam air demineralisasi hingga volume 100 $\mathrm{mL}$. Formula larutan polietilena glikol (PEG) dibuat dengan melarutkan 50 gram PEG (BM 1000) dengan sedikit air, kemudian ditambah 30 gram $\mathrm{N}$ metiloldihidroksietilenurea (N-MDHEU) dan 3 gram larutan katalis $\mathrm{MgCl}_{2}$ /asam sitrat, larutan terus diaduk dan diencerkan hingga volume $1000 \mathrm{~mL}$.

\section{Imobilisasi PCM pada kain}

Percobaan imobilisasi PCM pada sampel kain dilakukan menggunakan pendekatan teknis yang telah dilakukan Vigo dkk (1985) yakni pad-drycure, mengingat cara ini masih relevan dengan teknis yang masih banyak digunakan di industri tekstil hingga saat ini. ${ }^{6}$ Sampel kain yang digunakan untuk percobaan dipotong dengan ukuran $30 \times 40 \mathrm{~cm}$ kemudian direndam dalam formula larutan PEG selama kira-kira 1 menit sambil sesekali diaduk. Selanjutnya kain diproses padding (WPU 80-90\%), drying (suhu $100^{\circ} \mathrm{C}$ selama 3 menit) dan curing (suhu $150^{\circ} \mathrm{C}$ selama 3 menit).

\section{Karakterisasi dan Pengujian}

Karakterisasi dan pengujian performa kain poliester dilakukan dengan SEM untuk melihat morfologi kain. Sifat termal kain diuji dengan menggunakan alat differential scanning calorimeter (DSC) dengan rentang suhu $-30-80^{\circ} \mathrm{C}$ dan kecepatan $10^{\circ} \mathrm{C} /$ menit. Spektrometer fourier transform infrared (FTIR) digunakan untuk mengkarakterisasi gugus reaktif kain CDP serta kemungkinan adanya gugus baru yang muncul dari dari ikatan yang terjadi antara bahan yang digunakan dengan sampel kain. Pengujian tahan cuci PEG pada permukaan kain hasil percobaan dilakukan sesuai standar SNI ISO 105-C06.

\section{HASIL DAN PEMBAHASAN}

\section{Morfologi kain setelah perlakuan dengan PCM}

Untuk memastikan adanya deposit PCM pada permukaan sampel kain, maka dilakukan pengamatan secara mikroskopik menggunakan SEM sebelum dan sesudah perlakuan imobilisasi PCM. Hasilnya memperlihatkan bahwa deposit PCM tampak melekat pada permukaan serat kain sebagaimana pada Gambar 1. Deposit PCM pada kain poliester/CDP tampak berupa lapisan yang menyalut seluruh serat (Gambar 1b), sedangkan pada permukaan kain T/R deposit PCM dengan jelas lebih menempel pada serat rayonnya. 


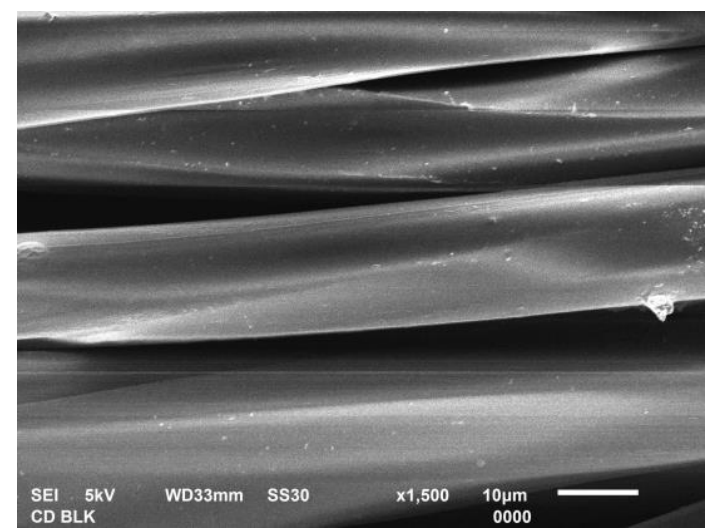

(a)

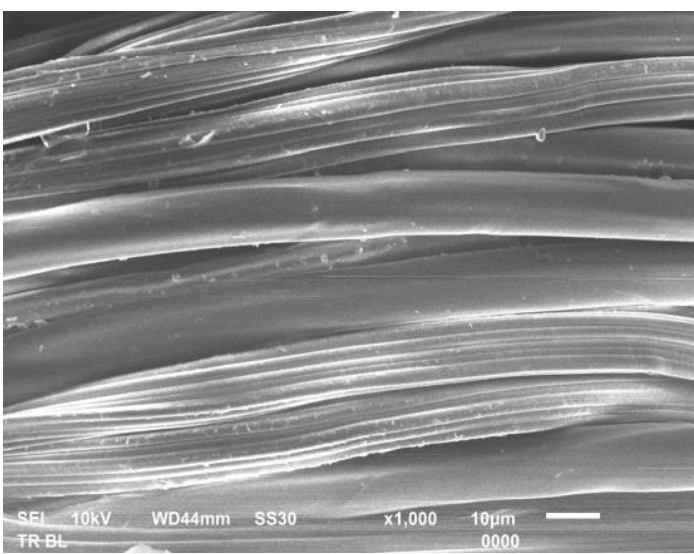

(c)

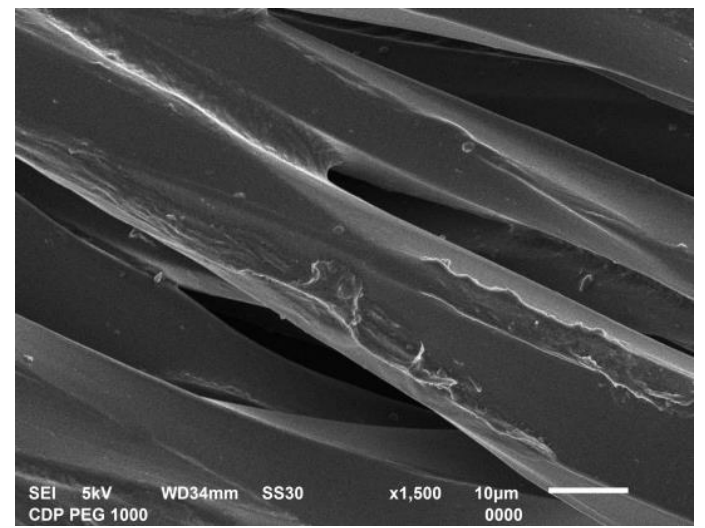

(b)

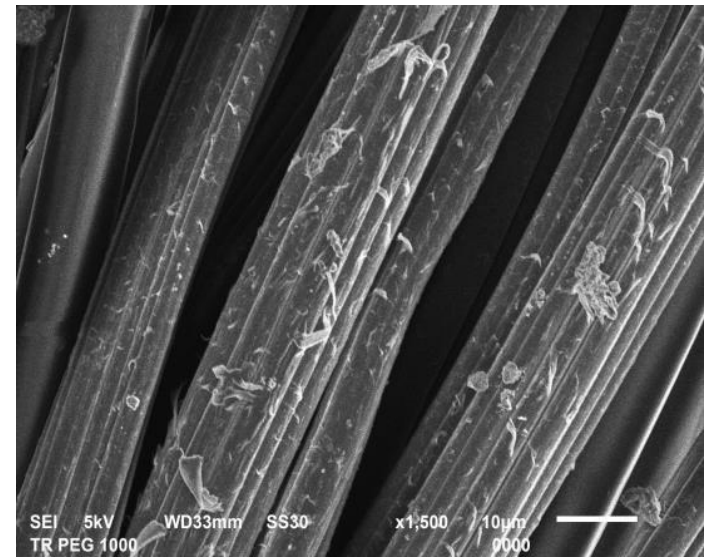

(d)

Gambar 1. Hasil SEM kain setelah perlakuan PCM (PEG 1000/N-MDHEU). a) Kain poliester/CDP (blanko), b) Kain poliester/CDP dengan perlakuan PCM, c) Kain T/R (blangko), dan d) Kain T/R dengan perlakuan PCM

Penambahan berat sampel kain hasil percobaan sebagai akibat perlakuan dengan PCM (PEG/N-MDHEU) menggunakan teknik pad (WPU $80 \%)$ - dry $\left(100^{\circ} \mathrm{C}\right.$, selama 3 menit $)$ - cure $\left(150^{\circ} \mathrm{C}\right.$, selama 3 menit) dapat dilihat pada Tabel 1. Penambahan berat pada kain poliester/CDP setelah perlakuan PCM dibandingkan pada kain T/R menghasilkan nilai paling tinggi yakni sebesar 7,6\%
Hal ini diduga berhubungan dengan sifat gugus reaktif yang terkandung dalam jenis serat kainnya. Pada kain poliester/CDP gugus $\mathrm{SO}_{3}^{-}$yang terkandung pada serat CDP berperan dalam melakukan ikatan silang dengan PEG/N-MDHEU, sedangkan pada kain $\mathrm{T} / \mathrm{R}$ yang berperan adalah gugus $\mathrm{OH}$ yang berasal dari serat rayonnya.

Tabel 1. Penambahan berat kain hasil perlakuan PCM (PEG 1000/N-MDHEU)

\begin{tabular}{lccc}
\hline Jenis Kain & \multicolumn{2}{c}{ Berat Kain $\left(\mathbf{g} / \mathbf{c m}^{2}\right)$} & $\begin{array}{c}\text { Penambahan } \\
\text { berat kain }(\%)\end{array}$ \\
\cline { 2 - 3 } & $\begin{array}{c}\text { Sebelum } \\
\text { perlakuan PCM }\end{array}$ & $\begin{array}{c}\text { Setelah } \\
\text { perlakuan PCM }\end{array}$ & \\
\hline Poliester/CDP & 0,0172 & 0,0185 & 7,6 \\
Poliester/ rayon (T/R) & 0,0215 & 0,0222 & 3,3 \\
\hline
\end{tabular}




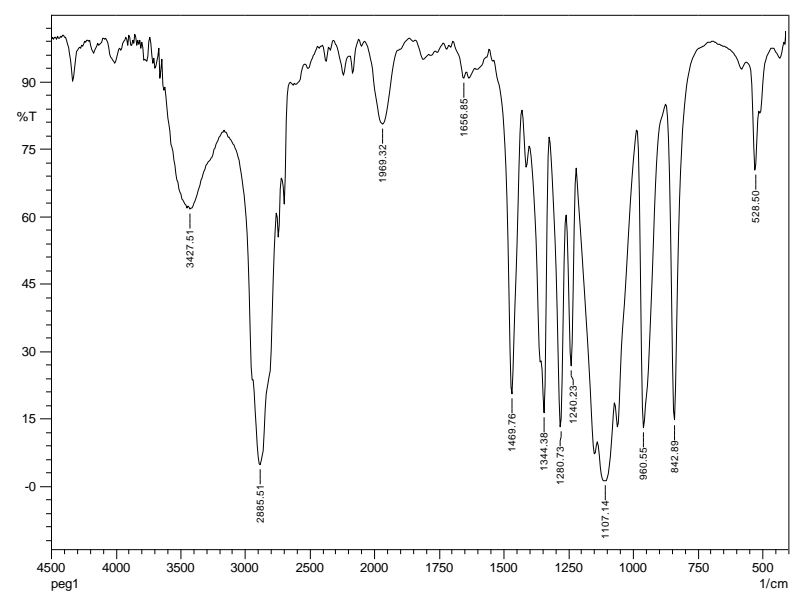

(a)

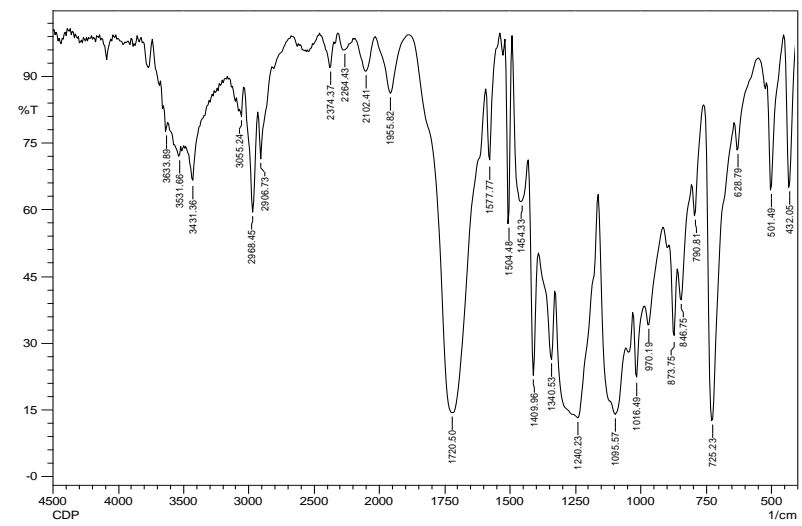

(c)

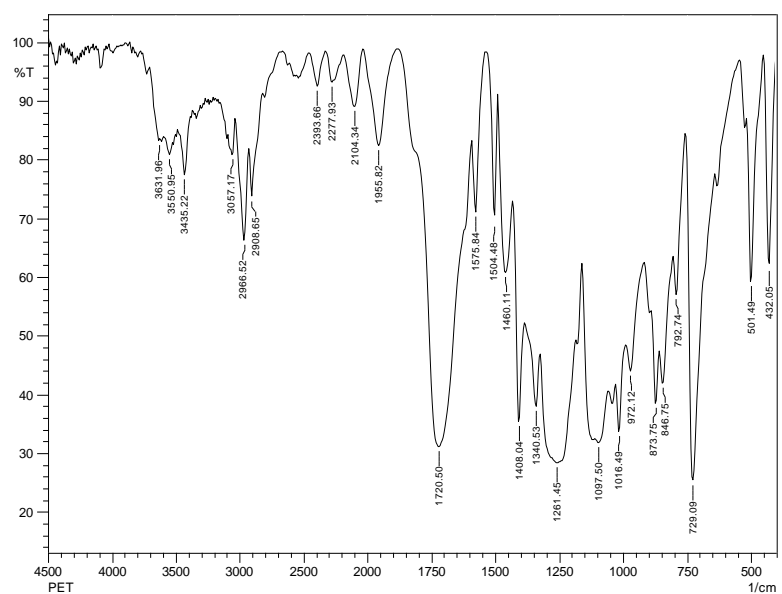

(b)

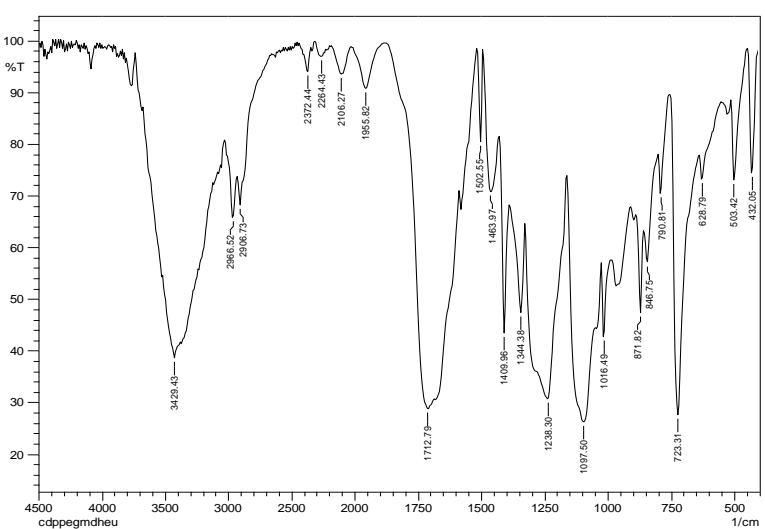

(d)

Gambar 2. Spektra FTIR: a) Polietilen glikol, b) Kain poliester (PET), c) Kain campuran Poliester/CDP, d) Kain campuran poliester/CDP dengan perlakuan PEG dan N-MDHEU.

Dari hasil percobaan dapat disimpulkan bahwa ikatan silang yang terjadi pada kain poliester/CDP lebih baik dibanding dengan ikatan silang yang terjadi pada kain T/R.

\section{Hasil uji FTIR}

Hasil pengukuran spektra FTIR PEG dan kain hasil percobaan dapat dilihat pada Gambar 2. Gugus fungsi yang terkandung dan terbaca hampir seluruhnya sama dari bahan PEG sebagai PCM, poliester dan poliester/CDP (Gambar 2-a, 2-b dan 2c) adalah gugus $\mathrm{OH}$, ulur $\mathrm{C}-\mathrm{H}$ alifatik, ulur $\mathrm{C}-\mathrm{O}$, dan tekuk C-O-H berturut-turut pada $3435-3431 \mathrm{~cm}^{-1}$, $1344-1340 \mathrm{~cm}^{-1}$ dan $1261-1240 \mathrm{~cm}^{-1}$. Regang $\mathrm{SO}_{3}$ dari CDP pada bilangan gelombang sekitar 1250 $\mathrm{cm}^{-1}$ bertumpang tindih dengan gugus $\mathrm{C}-\mathrm{O}$ sehingga menyebabkan intensitas dan lebar puncak menjadi lebih lebar. ${ }^{16}$ Gugus fungsi lainnya yang terbaca sama untuk poliester dan poliester/CDP adalah ulur $\mathrm{C}-\mathrm{H}$ aromatik, ulur $\mathrm{C}=\mathrm{O}, \mathrm{C}-\mathrm{C}$ aromatik, tekuk bidang $\mathrm{C}-\mathrm{H}$ aromatik dan tekuk keluar bidang $\mathrm{C}-\mathrm{H}$ aromatik berturut-turut pada 3055 dan $3057 \mathrm{~cm}^{-1}$, $1720 \mathrm{~cm}^{-1}, 1577$ dan $1454 \mathrm{~cm}^{-1}, 1097$ dan 1095 $\mathrm{cm}^{-1}$, serta 972 dan $790 \mathrm{~cm}^{-1}$. Gugus fungsi khas yang teridentifikasi hanya terdapat pada poliester/CDP adalah ikatan C-S aril pada $628 \mathrm{~cm}^{-1}$ (Gambar 2-c).

Pada kain campuran poliester/CDP yang telah mengalami perlakuan dengan PEG dan N-MDHEU sebagai crosslinking agent (Gambar 2-d) teridentifikasi adanya pergeseran dan perubahan intensitas serta lebar puncak gugus $\mathrm{OH}$ alkohol yang disebabkan oleh adanya PEG pada $3431 \mathrm{~cm}^{-1}$ menjadi $3429 \mathrm{~cm}^{-1}$. Gugus N-H yang berasal NMDHEU muncul terindentifikasi pada bilangan gelombang $1502 \mathrm{~cm}^{-1}$.

\section{Sifat termal kain hasil percobaan}

Analisis termal dengan menggunakan differential scanning calorimeter (DSC) dimaksudkan untuk mengetahui ada atau tidaknya serta sejauh mana peningkatan sifat penyerapan atau pelepasan panas laten dari sampel kain yang digunakan dalam percobaan aplikasi PCM ini. Kondisi proses pengujian DSC dilakukan pada rentang suhu $-20-80^{\circ} \mathrm{C}$ dengan kecepatan sebesar 
Tabel 2. Hasil uji sifat termal kain hasil percobaan

\begin{tabular}{lcccc}
\hline \multicolumn{1}{c}{ Jenis Kain } & $\begin{array}{c}\mathbf{T}_{(\mathbf{m})} \\
\left({ }^{\circ} \mathbf{C}\right)\end{array}$ & $\begin{array}{c}\Delta \mathbf{H}_{\mathbf{f}} \\
(\mathbf{J} / \mathbf{g})\end{array}$ & $\begin{array}{c}\mathbf{T}_{(\mathbf{c})} \\
\left({ }^{\circ} \mathbf{C}\right)\end{array}$ & $\begin{array}{c}\Delta \mathbf{H}_{\mathbf{c}} \\
(\mathbf{J} / \mathbf{g})\end{array}$ \\
\hline Poliester/ CDP & 36,95 & 4,98 & 20,06 & 5,30 \\
Poliester/ rayon(T/R) & 34,56 & 0,08 & 19,49 & 0,02 \\
\hline
\end{tabular}

Tabel 3. Hasil uji kain terhadap pencucian

\begin{tabular}{|c|c|c|c|c|c|c|}
\hline \multirow{3}{*}{ Jenis kain } & \multirow{2}{*}{$\begin{array}{c}\text { Sebelum } \\
\text { perlakuan } \\
\text { PCM-PEG }\end{array}$} & \multicolumn{5}{|c|}{$\begin{array}{c}\text { Setelah perlakuan dengan PCM-PEG } \\
\text { (Jumlah pencucian setara pencucian rumah tangga) }\end{array}$} \\
\hline & & $\begin{array}{l}\text { Sebelum } \\
\text { dicuci }\end{array}$ & $1 \mathrm{x}$ & $5 x$ & $10 x$ & $15 x$ \\
\hline & \multicolumn{6}{|c|}{ Berat kain $\left(\mathrm{g} / \mathrm{cm}^{2}\right)$} \\
\hline Poliester/CDP & 0,0170 & 0,0185 & 0,0167 & 0,0168 & 0,0166 & 0,0169 \\
\hline$T / R$ & 0,0214 & 0,0222 & 0,0208 & 0,0206 & 0,0207 & 0,0203 \\
\hline
\end{tabular}

$10^{\circ} \mathrm{C} /$ menit. Hasil pengujian kain menggunakan DSC dapat dilihat pada Tabel 2.

Dari Tabel 2 tampak bahwa kain poliester/CDP yang mengalami perlakuan dengan PEG 1000/N-MDHEU/katalis teridentifikasi adanya aktivitas termal pada pengujian menggunakan DSC pada rentang suhu $-30-80^{\circ} \mathrm{C}$. Kain poliester/CDP sifat pelelehan dan kristalisasi berturut-turut $\mathrm{T}(\mathrm{m})=$ $36,95^{\circ} \mathrm{C}$ dan $\mathrm{T}(\mathrm{c})=20,06^{\circ} \mathrm{C}$ dengan nilai $\Delta \mathrm{Hf}=4,98$ $\mathrm{J} / \mathrm{g}$ dan $\Delta \mathrm{Hc}=5,30 \mathrm{~J} / \mathrm{g}$. Serat kain poliester/CDP meskipun sedikit mengandung gugus $\mathrm{OH}$ akan tetapi cukup tinggi mengandung gugus negatif $\mathrm{SO}_{3}$ (gugus sulfonat) yang dapat melakukan ikatan silang dengan PEG/N-MDHEU. Demikian pula halnya yang terjadi pada sampel kain $\mathrm{T} / \mathrm{R}$ yang memperlihatkan sifat termal dengan nilai $\mathrm{T}(\mathrm{m})=34,56^{\circ} \mathrm{C}$ dan $\mathrm{T}(\mathrm{c})=$ $19,49^{\circ} \mathrm{C}$ dengan nilai $\Delta \mathrm{Hf}=0,079 \mathrm{~J} / \mathrm{g}$ dan $\Delta \mathrm{Hc}=$ $0,024 \mathrm{~J} / \mathrm{g}$. Serat kain T/R mengandung lebih banyak gugus $\mathrm{OH}$ dibanding dengan serat poliester $100 \%$ yang berasal dari serat rayonnya. Jika dibandingkan jumlah panas pelelehan/kristalisasi yang terjadi antara sampel kain poliester/CDP dan T/R, maka kain poliester/CDP memiliki nilai $\Delta \mathrm{Hf}$ dan $\Delta \mathrm{Hc}$ lebih besar.

\section{Hasil uji terhadap ketahanan pencucian}

Hasil uji tahan cuci terhadap sampel kain yang telah mengalami perlakuan dengan PEG berdasarkan cara uji yang berlaku dapat dilihat pada Tabel 3. Keberadaan PEG pada permukaan kain dilakukan dengan cara penimbangan. Selisih berat kain sebelum dilakukan pencucian dan setelah pencucian diasumsikan sebagai berat PEG yang menempel pada permukaan kain. Tampak bahwa penurunan berat kain setelah pencucian hingga $15 \mathrm{x}$ setara pencucian rumah tangga tidak terjadi secara gradual, dimana berat kain hasil pencucian $1 \mathrm{x}$ (kali) hingga pencucian $15 \mathrm{x}$ setara pencucian rumah tangga tidak menunjukkan perbedaan yang signifikan. Kesimpulannya adalah bahwa ketahanan PEG pada permukaan kain terhadap pencucian belum memenuhi standar yang baik. Dengan kata lain bahwa pada pencucian 1 kali saja PM-PEG telah hilang pada permukaan kain. Hal ini disebabkan karena sifat crosslinker N-MDHEU yang kurang kuat dibandingkan dengan crosslinker DMDHEU, dimana pada pada N-MDHEU hanya mengandung satu gugus metilol, sedangkan pada DMDHEU mengandung 2 gugus metilol yang berperan dalam proses ikatan silang dengan PEG dan gugus reaktif $\left(\mathrm{O}^{-}\right.$dan $\left.\mathrm{SO}_{3}^{-}\right)$pada serat kain.

\section{KESIMPULAN}

Formulasi larutan PCM PEG/NMDHEU/katalis $\mathrm{MgCl}_{2}$ dapat aplikasikan sebagai PCM pada kain campuran poliester/CDP dan T/R. Hal ini terbukti dari hasil analisis DSC pada rentang temperatur $-30-80^{\circ} \mathrm{C}$, sampel kain hasil percobaan memiliki aktivitas termal, yakni menyerap dan melepas panas laten. Kain poliester/CDP hasil percobaan memiliki aktivitas termal laten dengan nilai $\mathrm{T}(\mathrm{m})=36,95^{\circ} \mathrm{C}$ dan $\mathrm{T}(\mathrm{c})=20,06^{\circ} \mathrm{C}$, sedangkan kain $\mathrm{T} / \mathrm{R}$ dengan nilai $\mathrm{T}(\mathrm{m})=34,56^{\circ} \mathrm{C}$ dan $\mathrm{T}(\mathrm{c})=$ $19,49^{\circ} \mathrm{C}$. Hasil analisis menggunakan SEM 
memperlihatkan bahwa polietilena glikol (PEG) tampak sebagai deposit yang menempel pada permukaan serat kain. Pengujian ketahanan terhadap pencucian, baik kain poliester/CDP maupun T/R hasil percobaan memperlihatkan hasil yang belum memuaskan, dimana pada 1 kali pencucian setara pencucian rumah tangga PEG telah menghilang dari permukaan kain.

\section{UCAPAN TERIMAKASIH}

Penelitian ini terlaksana dengan bantuan anggaran penelitian DIPA Balai Besar Tekstil tahun 2019 .

\section{PUSTAKA}

1. Mondal, S. Phase change materials for smart textiles - An overview. Appl. Therm. Eng. 28, 1536-1550 (2008).

2. Sarier, N. \& Onder, E. Organic phase change materials and their textile applications: An overview. Thermochim. Acta 540, 7-60 (2012).

3. Arjun, D. \& Hayavadana, J. Thermal energy storage materials (PCMs) for textile application. J. Text. Appar. Technol. Manag. 8, (2014).

4. Iqbal, K. et al. Phase change materials, their synthesis and application in textiles - a review. J. Text. Inst. 110, 625-638 (2019).

5. Prajapati, D. G. \& Kandasubramanian, B. A Review on Polymeric-Based Phase Change Material for Thermo-Regulating Fabric Application. Polym. Rev. 60, 389-419 (2020).

6. Vigo, T. L. \& Frost, C. M. TemperatureAdaptable Fabrics. Text. Res. J. 55, 737-743 (1985).

7. Seifpoor, M., Nouri, M. \& Mokhtari, J. Thermoregulating nanofibers based on nylon 6,6/polyethylene glycol blend. Fibers Polym. 12, 706-714 (2011).

8. Chen, C., Wang, L. \& Huang, Y. Electrospun phase change fibers based on polyethylene glycol/cellulose acetate blends. Appl. Energy 88, 3133-3139 (2011).

9. Chen, C., Zhao, Y. \& Liu, W. Electrospun polyethylene glycol/cellulose acetate phase change fibers with core-sheath structure for thermal energy storage. Renew. Energy 60, 222225 (2013).

10. Chen, H., Ma, Q., Wang, S., Liu, H. \& Wang, K. Morphology, compatibility, physical and thermo-regulated properties of the electrospinning polyamide 6 and polyethylene glycol blended nanofibers. J. Ind. Text. 45, 1490-1503 (2014).

11. Ghosh, S. \& Bhatkhande, P. Encapsulation of PCM for thermo-regulating fabric application. Fiber Soc. 2012 Spring Conf. Fiber Res. Tomorrow's Appl. 2012, 366-370 (2012).

12. Kuru, A. \& Aksoy, S. A. Cellulose-PEG grafts from cotton waste in thermo-regulating textiles. Text. Res. J. 84, 337-346 (2014).

13. Sarier, N. et al. Production of PEG grafted PAN copolymers and their electrospun nanowebs as novel thermal energy storage materials. Thermochim. Acta 643, 83-93 (2016).

14. Sundararajan, S., Samui, A. B. \& Kulkarni, P. S. Synthesis and characterization of poly(ethylene glycol) acrylate (PEGA) copolymers for application as polymeric phase change materials (PCMs). React. Funct. Polym. 130, 43-50 (2018).

15. Vigo, T. L. \& Bruno, J. S. TemperatureAdaptable Textiles Containing Durably Bound Polyethylene Glycols. Text. Res. J. 57, 427-429 (1987).

16. Sun, Y. et al. Strctures and properties of modification copolyester fiber. Adv. Mater. Res. 301-303, 104-108 (2011). 